\title{
CAVEOLIN-1 IN TUMOUR CELLS IS PREDOMINATELY EXPRESSED IN THE BASAL SUBTYPE OF TRIPLE-NEGATIVE BREAST CARCINOMA
}

\author{
Savelina L. Popovska, \\ Ivan N. Ivanov, \\ Akishi Ooi ${ }^{1}$ \\ Department of Pathology, \\ Medical University - Pleven, \\ Bulgaria \\ ${ }^{1}$ Department of Molecular Pathology, \\ Kanazawa Medical University, \\ Japan
}

\begin{abstract}
Summary
Triple-negative breast cancer (TNBC) is a subtype of breast cancer which is clinically negative for expression of steroid hormones and HER2 protein. According to DNA microarray profiling, breast cancer was divided into several molecular subgroups, including Luminal A and Luminal B; HER2 overexpressing; normal breastlike and basal-like subtype. TNBC comprises tumours that express heterogeneous molecular and immunohistochemical phenotype, thus determining different prognosis. The majority of TNBC carry the "basal-like" molecular profile on gene expression arrays. Basal-like carcinomas of the breast associated with poor prognosis often correlate with expression of Caveolin-1. The study aimed to investigate the expression of caveolin-1 in the tumour cells and in the stromal component of the tumour among the group of TNBC and compare it to the expression of caveolin-1 in a control group with non-TN breast cancer. Whole tissue sections were used. Formalin fixed, paraffin embedded tissue materials from 101 patients diagnosed with invasive breast cancer during the period 2004-2007 were investigated in a retrospective study. A multistep approach was used to separate the different subtypes of breast cancer. During the first step the breast tumours were separated according to their ER, PgR, HER 2 and proliferative activity, using the Ki-67 index. The triplenegative tumours were additionally tested for EGFR and CK5/6. The basal breast cancer group was finally subdivided into basal and baso-luminal according to the type of expression of basal cytokeratins. caveolin-1 expression was examined in the tumour parenchyma and stroma. According to our results, caveolin-1 expression in breast cancer was significantly associated with basal biomarkers expression (basal and baso-luminal type of BC) $\chi^{2}=33.4 ; p<0.0001$.Caveolin- 1 can be used as a potential marker to examine the presence of basal phenotype in breast cancer.
\end{abstract}

Key words: caveolin, immunohistochemistry, stromal cells, triple-negative breast cancer

\section{Introduction}

Triple-negative breast cancer (TNBC) is a subtype of breast cancer that is clinically negative for expression of steroid hormones and HER2 protein. High grade TNBC is characterized by a heterogeneous molecular profile, aggressive behavior, and distinct patterns of metastasis and lack

Received: October 08, 2014

Revision received: October 28, 2014

Accepted: November 24, 2014 
of targeted therapies.

According to DNA microarray profiling, breast cancers are divided into several molecular subgroups, including Luminal A and Luminal B, HER2 overexpressing, normal breast-like, and basal-like subtypes [1].

Triple negative carcinomas of the breast are defined as a group of tumours not expressing predictive biological markers (ER, PgR and HER2-negative). This definition is suboptimal (from a clinical point of view) and could explain the emerging sub-stratification of this category [2].

During the last couple of years it was shown that the category of TNBC is comprised of tumours that express heterogeneous phenotype, therefore, determining a different prognosis [2].

Although not synonymous, the majority of TNBCs carry the "basal-like" molecular profile on gene expression arrays.

Using immunohistochemistry (IHC) the basal subtype in particular, is defined as positive for basal cytokeratins (CKs) $-\mathrm{CK} 5 / 6$, CK14, and/or CK17; negative for ER, PR, and HER2 in triple negative (TN) classification and positive for CK5/6, CK14, CK17, and/or EGFR; and negative for $\mathrm{ER}, \mathrm{PR}$, and HER2 in $\mathrm{CK} / \mathrm{TN}$ classification [3].

We developed an IHC panel of markers to help identify biological subtypes of basal BC and make them distinguishable even in routine practice [4].

Heterogeneity in basal cytokeratin expression, as described by Laakso Metal., may be used to define two distinct subtypes: basal and baso-luminal. The latter have been reported as associated with distinctive features related to oncogene and biomarker status, proliferation activity, and clinical patient survival [4].

Caveolin-1 represents a scaffolding protein, a member of the caveolines family, which is one of the proteins coating plasma membrane invaginations termed "caveolae".

Caveolae represent invaginations of the plasma membrane, which are 50 to $100 \mathrm{~m}$ in size. It is assumed that these morphological units serve as cell-membrane organizing centres. The physiological role of caveolae was systematically studied during the last six decades (reviewed in [5]). Calveolae are mainly involved in cholesterol homeostasis, vesicular transport and signal transduction within the cell.

In the normal breast, caveolae and, respectively, Caveolin-1, are found in a subset of epithelial and mesenchymal cells including: basal cells, myoepithelial cells of the ductolobular system of the breast, endothelial cells, fibroblasts and adipocytes of the breast stroma. Caveolin-1 and 2 are described to be strongly associated with basal-like breast cancer and triple-negative immunophenotype [6].

The distribution of caveolin-1 in normal breast tissue, benign breast lesions and breast cancer precursors is controversial [7-15].

Pinilla et al. [10] have recently shown that caveolin-1 is expressed in approximately $4 \%$ of all invasive breast carcinomas, being particularly prevalent in tumours with basal-like/ myoepithelial differentiation. On the other hand, Park et al. [9] described caveolin-1 membrane and cytoplasmic expression in normal luminal epithelial cells and in $57 \%$ of invasive breast cancers.

In this report, caveolin-1 expression was inversely correlated with human epidermal growth factor receptor (EGFR) and (HER2) or EGFR overexpression. However, the antibody and immunohistochemical methods used were not validated [9]. The application of Cav-1 for basal breast cancer identification was also mentioned by Bertucci $\mathrm{F}$ et al. [13].

Savage et al. have also reported that basallike carcinomas of the breast were associated with the expression of caveolin-1[15].

Later, Elsheikh et al. proved that the expression of caveolin-1 was associated with the expression of basal markers and lack of steroid hormone receptor positivity in breast carcinomas [6]. The expression of caveolin-1 in tumour cells was not associated with a decrease in overall survival [16], whereas other authors reported a positive correlation between preserved positivity in the tumour stroma and increased overall survival [11, 17-19].

We used whole tissue sections to compare the expression of caveolin-1 in tumour cells and in the stromal component of the tumours in TNBC patients and non-TNBC patients.

\section{Materials and Methods}

Formalin fixed, paraffin embedded tissue materials from 101 patients diagnosed with invasive breast cancer during the period 20042007 were studied retrospectively.

A multistep approach to separate the different subtypes of breast cancer was used.

During the first step, the breast tumours were divided into groups according to their ER, PgR, 
HER 2, and their proliferative activity according to Ki-67 index as follows: negative for ER, PR, and HER2 in triple negative group (TN); Luminal A (ER+ve, HER 2-ve, Ki-67 index $<15 \%$ (low proliferation); Luminal B (ER+ve, HER 2 -ve or + ve, Ki-67 index $\geqslant 15 \%$ (high proliferation) and HER 2 non-luminal, overexpressing subtype (ER-ve, HER 2+ve).

Then, TN tumours were additionally tested for EGFR and CK5/6, and the TN group was subdivided into basal (positive for EGFR/or CK5/6) and non-basal (negative for EGFR and CK5/6) BC [20].

The basal breast cancer group was finally subdivided into basal and baso-luminal depending on the type of expression of basal cytokeratins. If one tumour was uniformly positive for basal CKs, it was classified as purely "basal". If the tumour showed partially positivity for basal CKs, it was assumed to be of the "basoluminal" type [4].

Cases were classified as positive if membranous staining of $\geqslant 5 \%$ of tumour cells were found positive (with or without cytoplasmic reactivity). The expression of caveolin-1 in the tumour cells and the tumour stroma was assessed and compared to the subtypes of breast cancer.

Immunohistochemical assessment of the studied markers was carried out according to the protocols of the manufacturer (Table 1).

Table 1. Antibody, Clone, Dilution and Manufacturer

\begin{tabular}{llll}
\hline Antibody & Clone & Dilution & Manufacturer \\
\hline ER & Mouse AntiHuman 1D 5 & Ready to use & DakoCytomation \\
\hline PgR & PR-PgR 636 Mouse AntiHuman & Ready to use & DakoCytomation \\
\hline HER-2 & $\begin{array}{l}\text { Polyclonal AntiHuman c-erb-B- } \\
\text { 2 Oncoprotein 1100 }\end{array}$ & DakoCytomation \\
\hline Caveolin-1 & Caveolin-1 clone 2297 & $1: 100$ & BD Transduction Lab \\
\hline Cytokeratin 5/6 & $\begin{array}{l}\text { Anti-human Cytokeratin 5/6- } \\
\text { clone D5/16 B4 }\end{array}$ & Dako Cytomation \\
\hline EGFR & $\begin{array}{l}\text { Mouse monoclonal -clone 18C9 } \\
\text { NOVO }\end{array}$ & $1: 100$ & DakoCytomation \\
\hline
\end{tabular}

The Ki-67 labelling index was evaluated as follows: low proliferation $<15 \%$, high proliferation $\geqslant 15 \%$.

CK5/6 were classified as negative $(<5 \%)$, heterogeneously positive (5-69\%), or uniformly positive $(>70 \%$ of immunopositive tumour cells).

ER and PgR were considered positive if more than $1 \%$ of the tumour cells demonstrated a weak positivity, at the least.

EGFR and HER 2 immunohistochemistry was scored in a four-step scale $(0,1+, 2+$, and $3+)$, and $2+$ and $3+$ scores were regarded as positive for overexpression of the protein.

HER-2 and EGFR gene amplification was assumed when chromogenic in situ hybridization revealed six or more gene copies per cell in at least $10 \%$ of the tumour cells.

The statistical analyses were performed using Statgraph plus 2.0. software.

\section{Results}

Thirty-eight out of the studied 101 tumours $(37.62 \%)$ were found positive for steroid hormone receptors. Twenty-three of all studied tumours were found to be HER2 positive $(22.77 \%)$ and 52 cases were triple negative (51.48\%).

EGFR was found to be overexpressed in 26 cases $(25.74 \%)$, while it was negative in 75 $(74.26 \%)$ of the cases. CK 5 was found to be negative in 56 cases $(55.45 \%)$, focally positive in $7(6.93 \%)$ and positive in 38 cases (37.62\%). Tumours were stratified according to their ER, PgR or/and HER 2 positivity into Luminal A\&B, HER 2 overexpressing, and triple negative phenotype (Table 2). Then, according to their EGFR, CK 5/6, expression tumours were additionally stratified as shown Table 3 . 
Popovska S., et al. Caveolin-1 in tumour cells is predominately expressed...

Table 2. Stratification of the tumours according to their immunohistochemical phenotypes

\begin{tabular}{lllll}
\hline $\begin{array}{l}\text { Substratification } \\
\text { according to } \\
\text { posit ivit y for ER, }\end{array}$ & $\begin{array}{l}\text { Number of } \\
\text { patients }\end{array}$ & Luminal A\&B & HER 2 & TN BC \\
\cline { 2 - 5 } \begin{tabular}{l} 
PgR or/a nd HER \\
\cline { 2 - 5 }
\end{tabular} & $\mathrm{N}=101$ & $38(37.62 \%)$ & $11(10.89 \%)$ & $52(51.48 \%)$ \\
\hline
\end{tabular}

Table 3. Stratification of the tumours according to the CKs expression pattern

\begin{tabular}{lllll}
\hline $\begin{array}{l}\text { Substratification } \\
\text { according to CK } \\
\text { expression pat tern }\end{array}$ & $\begin{array}{l}\text { Number of } \\
\text { patients }\end{array}$ & Basa l & Baso -luminal & $\begin{array}{l}\text { Null } \\
\text { phenotype }\end{array}$ \\
\cline { 2 - 5 } & $52(51.48 \%)$ & $41(40.59 \%) *$ & $9(8.91 \%) *$ & $2(1.98 \%) *$ \\
\hline
\end{tabular}

* $\%$ from the studied population

In normal non-cancerous mammary tissues, caveolin-1 was found to be expressed in myoepithelial and basal cells of the ducto-lobular system of the breast and endothelial cells, fibroblasts and adipocytes of the breast stroma (Fig. 1).

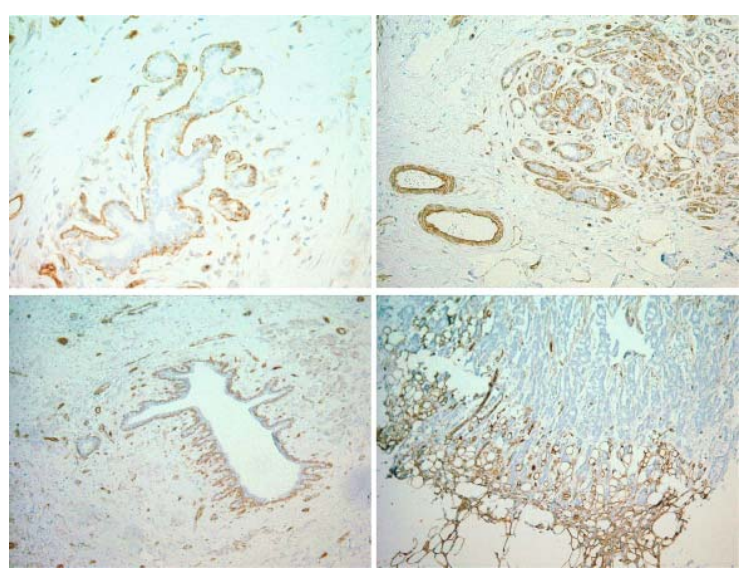

Figure 1. Expression of caveolin-1 in myoepithelial and basal cells of the ducto-lobular system $(\mathrm{A}, \mathrm{B}, \mathrm{C})$ of the breast and adipocytes (D) of the breast stroma. Immunostaining, anti- caveolin-1 antibody, magn. 200x

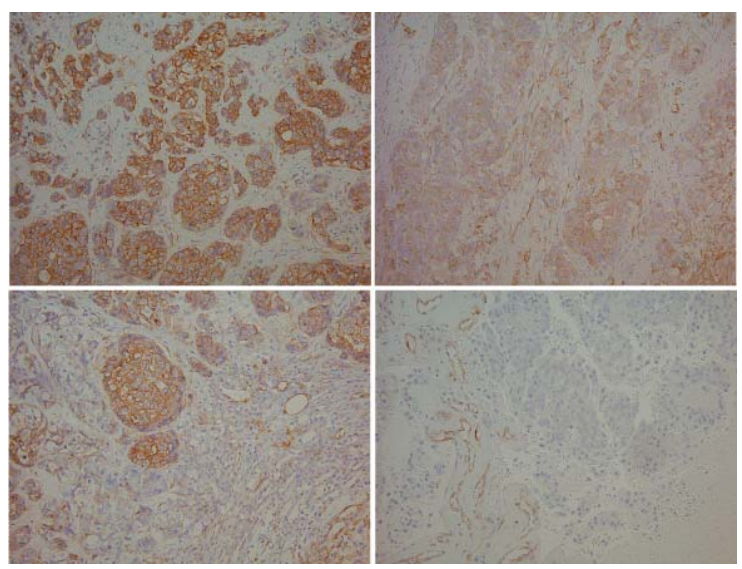

Figure 2. Diffuse, strong (A) and moderate expression (B) of caveolin-1 in tumour cells. Focal expression (C) and negative (D) immunostaining for caveolin-1.IHC, magn. 400x
Caveolin-1- staining in the tumour cells was found to be membranous, ranging from weak to intensive in the different tumours (Fig. 2). In some cases, the expression found was focal. In positive cases, caveolin-1 was found diffusely and strongly or moderately expressed in the tumour stroma. (Fig.3)

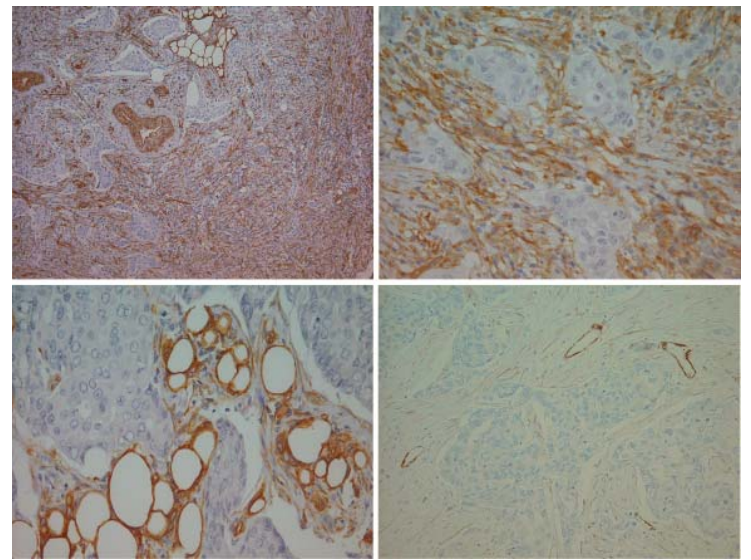

Figure 3. Diffuse and strong expression in stromal fibroblasts (A, B) of caveolin-1 C-Absence of caveolin-1 staining in the stromal fibroblast compartment, positive staining of fat cells. DNegative staining of stromal and tumour component. Only blood vessels as internal control were positively stained. IHC, magn. 200x

According to our results, caveolin-1 expression in breast cancer was significantly associated with basal biomarkers expression (basal and baso-luminal type of BC) $\chi^{2}=33.4$; $\mathrm{p}<0.0001 ; \mathrm{n}=101$, (Table 4).

The stromal expression of caveolin-1 in breast cancer was not specially related to any biological subtype of TN breast cancer $\chi^{2}=6.27 ; p=0.1798$; $\mathrm{n}=101$ (Table 4). The stromal positivity was associated with endothelial cells, myoepithelial cells and fibroblasts. 
Table 4. Distribution of caveolin-1 expression in tumour cell and stromal component in different tumour subtypes

\begin{tabular}{|c|c|c|c|c|c|c|c|}
\hline \multirow[t]{2}{*}{$\begin{array}{l}\text { Tumour } \\
\text { subtypes }\end{array}$} & \multirow{2}{*}{$\begin{array}{l}\mathrm{N}(\%) \\
\mathrm{N}=101 \\
\end{array}$} & \multicolumn{3}{|c|}{ Caveolin-1 in tumour cell expression } & \multicolumn{3}{|c|}{$\begin{array}{l}\text { Caveolin-1 in tumour stroma } \\
\text { expression }\end{array}$} \\
\hline & & + tre & -ve & P value & +ve & -ve & P value \\
\hline $\begin{array}{l}\text { Luminal } \\
\text { A\&B }\end{array}$ & $38(37.62 \%)$ & $0(0 \%)$ & $38(37.62 \%)$ & \multirow[t]{5}{*}{$\begin{array}{l}\chi 2=33.4 \\
p<0.0001\end{array}$} & $30(29.70 \%)$ & $8(7.92 \%)$ & \multirow[t]{5}{*}{$\begin{array}{l}\chi 2=6.27 \\
p=0.1798\end{array}$} \\
\hline Her2 & $11(10.89 \%)$ & $0(0 \%)$ & $11(10.89 \%)$ & & $10(9.90 \%)$ & $1(0.99 \%)$ & \\
\hline Basal & $41(40.59 \%)$ & $20(19.80 \%)$ & $21(20.79 \%)$ & & $25(24.75 \%)$ & $16(15.84 \%)$ & \\
\hline $\begin{array}{l}\text { Baso- } \\
\text { luminal }\end{array}$ & $9(8.91 \%)$ & $1(0.99 \%)$ & $8(7.92 \%)$ & & $6(5.94 \%)$ & $3(2.97 \%)$ & \\
\hline $\begin{array}{l}\text { Null } \\
\text { phenotype }\end{array}$ & $2(1.98 \%)$ & $0(0 \%)$ & $2(1.98 \%)$ & & $2(1.98 \%)$ & $0(0 \%)$ & \\
\hline
\end{tabular}

\section{Discussion}

The definition of TNBC is an immunohistochemical diagnosis made "per exclusion". It is based on IHC negativity for steroid hormonal receptors $-\alpha$ ER, PgR, and HER2.

The absence of caveolin-1 in the luminal epithelium and its marked expression in the myoepithelial cells suggested the possible application of caveolin-1 as a myoepithelial cell marker in clinical practice.

Although the application of IHC staining for breast cancer expression profiling and substratification seems to be useful and applicable in routine practice, we believe it should be precisely specified first.

The expression of caveolin-1 in breast carcinomas is strongly associated with the expression of "basal" phenotype. As our study proves, baso-luminal and basal subtypes of TNBC are those likely to express caveolin-1. Our findings were consistent with other relevant literature data [6].

The above mentioned subtypes form the largest fraction of triple negative breast carcinomas. The remaining subtype of $\mathrm{TN}$ breast cancer (null phenotype) was found to be negative for caveolin-1.

The relationship between caveolin-1 and basal phonotype suggests that this marker can be used as a basal cell marker in routine practice. Unfortunately, tumour cell expression of caveolin-1 was found lacking in less than half of the basal tumours and over two-thirds of the baso-luminal type. This comes to suggest that caveolin-1 expression would be useful for determining only a fraction of basal phenotype expressing tumours (basal/basoluminal biological phenotypes). However, we believe that Caveolin-1 may be reasonably set in imunohistochemical panels for biological phenotyping of breast cancer.

The presence of both caveolin-1 positive and negative breast cancers suggests that basal and basal luminal types may eventually be divided in basoluminal, caveolin-1 positive/ negative and basal caveolin-1 positive/negative, respectively. Such distribution is of uncertain value in clinical practice. Further investigations are needed to reveal the biological value of caveolin-1 expression in basal phenotype expressing breast tumours. According to recent studies, TN patients with high levels of stromal expression of caveolin-1 had a good clinical outcome [17].

Debates on varying prognostic significance of caveolin-1 expression in the tumour are unlikely to end up with a simple answer. Prior to introducing evaluation of stromal caveolin-1 positivity, a consistent evaluation methodology should be agreed upon.

Tumour stroma positivity for caveolin-1 among the group of TNBCs was found to be related mainly to endothelial cells of blood capillaries, which are almost constantly persistent in the tumour stroma. We did not accept this as true stromal positivity. Instead, we considered the tumour stroma positive for caveolin-1 if it was expressed in tumour stromal fibroblasts. Of particular interest are cases in which myoepithelial and basal cells of the normal stroma are entrapped in the infiltrated tumour.

According to Simpkins SA et al., the loss of Cav -1 expression in breast cancer-associated fibroblasts is associated with poor prognosis [11], 
and other studies support this idea [17-19]. The expression of caveolin-1 by the tumour stroma did not show any specific predominance in none of the studied subtypes. It seems that positivity of the stroma refers to other more complex properties of the tumour rather than the tumour type alone. It may also be an indicator of normal stroma preservation in the process of tumour invasion and normal stromal matrix remodeling.

\section{Conclusion}

In conclusion, this study supports the idea that caveolin-1 can be used as a basal marker for breast cancer. Although it is not likely to substitute the widely approved basal markers EGFR and CK 5/6, it can be applied in more extended IHC panels for breast cancer subtyping. The subdividing of basal and baso-luminal breast cancer into caveolin-1 positive and caveolin-1 negative seems to be of uncertain value. Further investigation is needed to determine the prognostic importance of loss of caveolin-1 expression in stomal fibroblasts in breast cancer patients.

\section{References}

1. O'Brien KM, Cole SR, Tse CK, Perou CM, Carey LA, Foulkes WD, et al. Intrinsic breast tumour subtypes, race, and long-term survival in the Carolina Breast Cancer Study. Clin Cancer Res. 2010;16(24):6100-10. doi: 10.1158/10780432.CCR-10-1533.

2. Metzger-Filho O, Tutt A, de Azambuja E, Saini KS, Viale G, Loi S, et al. Dissecting the heterogeneity of triple-negative breast cancer. J Clin Oncol. 2012;30(15):1879-87. doi: 10.1200/ JCO.2011.38.2010.

3. Tang P, Wang J, Bourne P. Molecular classifications of breast carcinoma with similar terminology and different definitions: are they the same? Hum Pathol. 2008;39(4):506-13.

4. Laakso M, Tanner M, Nilsson J, Wiklund T, Erikstein B, Kellokumpu-Lehtinen P, et al. Basoluminal carcinoma: a new biologically and prognostically distinct entity between basal and luminal. Clin Cancer Res. 2006; 12:4185-4191.

5. Cohen AW, Hnasko R, Schubert W, Lisanti MP. Role of caveolae and caveolins in health and disease. Physiol Rev. 2004;84(4):1341-79.
6. Elsheikh SE, Green AR, Rakha, Samaka RM, Ammar AA, Powe D, et al. Caveolin 1 and Caveolin 2 are associated with breast cancer basallike and triple-negative immunophenotype. $\mathrm{Br} \mathrm{J}$ Cancer. 2008; 99, 327-34. doi:10.1038/sj.bjc. 6604463.

7. Mercier I, Lisanti MP. Caveolin-1 and breast cancer: a new clinical perspective. Adv Exp Med Biol. 2012;729:83-94. doi: 10.1007/978-1-46141222-9 6.

8. Golshahi H, Tavasoli A, Rezaie A, Farhadi M. Immunohistochemical study of expression of caveolin-1 in canine malignant mammary tumour. Comp Clin Pathol. 2013;22 (5):971-6.

9. Park SS, Kim JE, KimYA, KimYC, Kim SW. Caveolin-1 is down-regulated and inversely correlated with HER2 and EGFR expression status in invasive ductal carcinoma of the breast. Histopathology. 2005;47: 625-30.

10. Pinilla SM, Honrado E, Hardisson D, Benitez J, Palacios J. Caveolin-1expression is associated with a basal-like phenotype in sporadica nd hereditary breast cancer. Breast Cancer ResTreat. 2006;99:85-90.

11. Simpkins SA, Hanby AM, Holliday DL, Speirs V. Clinical and functional significance of loss of caveolin-1 expression in breast cancer-associated fibroblasts. J Pathol. 2012;227(4):490-8.

12. Mercier I, Bryant KG, Sotgia F, Bonuccelli G, Witkiewicz AK, Dasgupta A, et al. Using Caveolin-1 epithelial immunostaining patterns to stratify human breast cancer patients and predict the Caveolin-1 (P132L) mutation. Cell Cycle. 2009;8(9):1396-401.

13. Bertucci F, Finetti P, Birnbaum D. Basal breast cancer: a complex and deadly molecular subtype. Curr Mol Med. 2012;12(1):96-110.

14. Hurlstone AF, Reid G, Reeves JR, Fraser J, Strathdee G, Rahilly M, et al. Analysis of the CAVEOLIN-1gene at human chromosome 7q31.1 in primary tumours and tumour-derived cell lines. Oncogene. 1999;18910):1881-90.

15. Savage K, Savega K, Lambros MB, Robertson D, Jones RL, Jones C, Mackay A, et al. Caveolin 1 is overexpressed and amplified in a subset of basallike and metaplastic breast carcinomas: a morphologic, ultrastructural, immunohistochemical, and in situ hybridization analysis. Clin Cancer Res. 2007;13(1):90-101.

16. Liedtke C, Kersting C, Bürger H, Kiesel L, Wülfing P, et al. Caveolin-1 expression in benign and malignant lesions of the breast. World J Surg Oncol. 2007;3(5):110.

17. Witkiewicz AK,Dasgupta A, Sotgia F, Mercier I, Pestell RG, Sabel M, et al. An absence of stromal caveolin-1 expression predicts early tumour recurrence and poor clinical outcome in human breast cancers. Am J of Pathol. 2009;174(6):202334.

18. Sotgia F, Martinez-Outschoorn UE, Pavlides S, 
Howell A, Pestell RG, Lisanti MP. Understanding the Warburg effect and the prognostic value of stromal caveolin-1 as a marker of a lethal tumor microenvironment. Breast Cancer Res. 2011, 13:213. doi:10.1186/bcr2892.

19. Howell A, Landberg G, Bergh J. Breast tumour stroma is a prognostic indicator and target for therapy Breast Cancer Res. 2009;11(Suppl 3):S16.
20. Cheang MC, Voduc D, Bajdik C, Leung S, McKinney S, Chia SK, et al. Basal-like breast cancer defined by five biomarkers has superior prognostic value than triple-negative phenotype. Clin Cancer Res. 2008;1;14(5):1368-76. doi: 10.1158/1078-0432.CCR-07-1658. 